\title{
Development of standardized methods for the analysis of amines, terpenes and ammonia in biomethane
}

\author{
Lorena Cuccia ${ }^{1,}$, Béatrice Sanz ${ }^{1}$, Dairo Ballestas Castro ${ }^{1}$, Jianrong Li $^{2}$, Adriaan M.H. van \\ der Veen ${ }^{2}$, Elena Amico di Meane ${ }^{3}$, Sergi Moreno ${ }^{3}$, Lucy P. Culleton ${ }^{3}$, Djimmy Vorin ${ }^{1}$, \\ Célia Senné ${ }^{1}$, Faiza Bougueroua $^{1}$, Laurent Pyrée $^{1}$, Yann Courtois ${ }^{1}$, and Christophe Tastard ${ }^{1}$ \\ ${ }^{1}$ : GRTgaz - Research and Innovation Center for Energy (RICE), 361 avenue du Président Wilson, \\ 93211 La Plaine Saint Denis, France \\ 2: VSL, Thijsseweg 11, 2629JA, Delft, the Netherlands \\ 3: National Physical Laboratory, Hampton Road, Teddington, Middlesex, UK, TW11 0LW
}

\begin{abstract}
European Commission targets specify that $32 \%$ of the European energy consumption should come from renewable sources by 2030. One of the most promising options to reach this target is gas generation from biomass, especially biomethane, for injection into natural gas grid. EN 16723 presents specifications for VOCs, corrosive components and compressor oil in biomethane, impurities monitored because of integrity of gas infrastructure and for health and safety reasons. Currently, it proposes test methods that are neither harmonized nor validated, and usually not dedicated to biomethane. Launched in June 2017, the EMPIR project 16ENG05 Metrology for Biomethane is aimed for specific, robust and standardized analytical methods development, along with novel and improved reference standards. The present paper focusses on the developed methods for the monitoring of amines, terpenes and ammonia involving $\mu \mathrm{GC}-\mathrm{TCD}$, TD-GC-MS and OFCEAS.
\end{abstract}

\section{Introduction}

One of the most promising technology to reach the European target of $32 \%$ of renewable energy share by 2030, is production of biomethane from biomass (e.g. biogas) [1]. Established in 2017, the EN 16723 standard presents specifications of biomethane for use in transport and for injection in the natural gas network [2]. These specifications concern VOCs, corrosive components and compressor oil in biomethane, impurities monitored for health and safety reasons. EN 16723 Part 1 currently proposes test methods that are neither harmonized nor validated, and usually not dedicated to biomethane. There is consequently a need to develop methods dedicated to biomethane, in order to meet the needs of the standard.

Launched in 2017, the EMPIR project 16ENG05 Metrology for Biomethane is aimed for specific, robust and standardized analytical methods development, along with novel and

\footnotetext{
*Corresponding author: lorena.cuccia@grtgaz.com
} 
improved reference standards. Seven groups of compounds are studied in the scope of the project: siloxanes, halogenated VOCs, terpenes, amines, ammonia, hydrogen fluoride, hydrogen chloride, compressor oil, as well as the study of the biogenic methane content. Thirteen partners are involved in this project, among which the Research and Innovation Center for Energy (RICE) of GRTgaz.

RICE GRTgaz is involved in the development of analytical methods for the monitoring of amines, ammonia and terpenes. Ammonia and amines, whose presence can be explained by biogas purification through amine technology process [3], present limitations of $10 \mathrm{mg} / \mathrm{m}^{3}$ in biomethane [2]. Terpenes are as well a class of compounds that have to be monitored in biomethane; in some cases, the concentration of terpenes in biomethane might be high enough to mask the odorisation of the fuel compounds as tetrahydrothiophene (THT) [4]. In the task of the present project, five terpenes, characteristics of biogas composition, were selected for the development of the method: $\alpha$ and $\beta$ pinene, 3 -carene, d-limonene, and $\mathrm{p}$ cymene [5]. Regarding amines, five were selected for the development of the method: ethanolamine (MEA), piperazine (PZ), methyldiethanolamine (MDEA), diethanolamine, and 2-(2-Aminoethoxy)ethanol (Diglycolamine, DGA).

The present paper aims at presenting the progress on the method development from RICE: TD-GC-MS method for amines, $\mu \mathrm{GC}$-TCD and TD-GC-MS methods for terpenes, and $\mu \mathrm{GC}$ TCD and OFCEAS methods for ammonia.

\section{Material and methods}

\subsection{Standards gas mixtures}

Ammonia gas mixtures were purchased from Air Products, at concentrations of 100, 12 and $10 \mathrm{mg} / \mathrm{m}^{3}$ in methane. Two terpenes mixtures were prepared and sent by the Gas and Particle Metrology Group of the National Physical Laboratory (NPL). The first mixture (mix 1), contained $\alpha$-pinene $(2.02 \mu \mathrm{mol} / \mathrm{mol}), \beta$-pinene $(1.98 \mu \mathrm{mol} / \mathrm{mol}), 3$-carene $(1.99 \mu \mathrm{mol} / \mathrm{mol})$, p-cymene $(2.00 \mu \mathrm{mol} / \mathrm{mol})$ and limonene $(2.02 \mu \mathrm{mol} / \mathrm{mol})$ in methane. The second mixture (mix 2), contained $\alpha$-pinene $(2.07 \mu \mathrm{mol} / \mathrm{mol}), 3$-carene $(2.00 \mu \mathrm{mol} / \mathrm{mol})$ and p-cymene $(2.03$ $\mu \mathrm{mol} / \mathrm{mol})$ in methane. Both mixtures contained $n$-octane at approximately $2 \mu \mathrm{mol} / \mathrm{mol}$ as a reference for stability. The mixtures were prepared in Air Products Experis passivated cylinders and pressurised at $7 \mathrm{MPa}$ (70 bar).

\subsection{Chemicals}

Individual solutions of ethanolamine (MEA), piperazine (PZ), methyldiethanolamine (MDEA), diethanolamine, and 2-(2-Aminoethoxy)ethanol (DGA) at $500 \mu \mathrm{g} / \mathrm{mL}$ in methanol were purchased from Restek. A mixture of the five amines in methanol at $100 \mu \mathrm{g} / \mathrm{mL}$ was as well purchased from Restek.

\subsection{Analytical method for amines measurement}

A TD-GC-MS method was developed for the monitoring of the five selected amines in biomethane. TD-GC-MS is composed of a thermodesorption system (TDS) from Gerstel, a 7890B Gas Chromatograph (GC) and a 5977B MSD Mass Spectrometer (MS) from Agilent. Three columns were tested for their ability to properly separate the compounds: Rtx-Volatile Amine ( $30 \mathrm{~m} \times 0.32 \mathrm{~mm} \times 0 \mu \mathrm{m})$, HP-5MS Ultra Inert and a DBWax (30m x 0.25mm x $0.5 \mu \mathrm{m})$. Helium was used as carrier gas in constant flow mode at $1 \mathrm{~mL} / \mathrm{min}$. The transfer line temperature to the MS detector was set at $280{ }^{\circ} \mathrm{C}$. Detection was performed with a mass 
spectrometer using electronic ionization (EI) source $(70 \mathrm{eV})$ heated to $230{ }^{\circ} \mathrm{C}$. The scan range was 25-250 amu. NIST spectra database was used for peak identification. Identification proposals were confirmed by the comparison with commercial standards.

\subsection{Analytical methods for terpenes: $\mu$ GC-TCD and TD-GC-MS}

Two methods, involving $\mu$ GC-TCD and TD-GC-MS, were developed in order to monitor terpenes in biomethane.

A $\mu \mathrm{GC}$ CP490 was purchased from Agilent. The selected column was CP-Sil 5CB (6 m), with helium as carrier gas. For the development of the method, the cylinder was directly connected to the $\mu \mathrm{GC}$. TD-GC-MS is composed of a thermodesorption system (TDS) from Gerstel, a 7890B Gas Chromatograph (GC) and a 5977B MSD Mass Spectrometer (MS) from Agilent. Prior to analysis, sampling was performed on Carbotrap C300 sorbents from Gerstel. The selected column was DB-624 (60m x $0.25 \mathrm{~mm}$ x $1.4 \mu \mathrm{m})$ with $6 \%$ cyanopropyl phenyl and $94 \%$ polydimethylsiloxane.

\subsection{Analytical methods for ammonia: $\mu$ GC-TCD and OFCEAS}

Tests were performed on a $\mu \mathrm{GC}-\mathrm{TCD}$ from MECI. The selected column was PPU $8 \mathrm{~m}$ LV with Helium as carrier gas. Analysis were realized by directly connecting the cylinder with the analyser. Tests were also performed on a ProCeas ${ }^{\circledR}$ from ap2e.

\section{Results}

\subsection{Amines analysis}

In order to select the most suitable column for the separation of the five amines, three columns were compared: Rtx-Volatile Amine $(30 \mathrm{~m}$ x $0.32 \mathrm{~mm}$ x $0 \mu \mathrm{m})$, HP-5MS Ultra Inert and a DBWax $(30 \mathrm{~m} \times 0.25 \mathrm{~mm} \times 0.5 \mu \mathrm{m})$. This step of the study was performed by liquid injections of amines solutions.

The HP-5MS Ultra Inert permitted a chromatographic separation in 13 minutes. However, MEA and DEA were not properly separated. The Rtx-Volatile Amine column was the most promising as it permitted a separation of the five amines in 25 minutes (Figure 1). For the separation, $\mathrm{GC}$ oven was initially heated at $40^{\circ} \mathrm{C}$ for $1.1 \mathrm{~min}$ then raised to $200^{\circ} \mathrm{C}$ (with $10^{\circ} \mathrm{C} / \mathrm{min}$ ) and maintained for $4,5 \mathrm{~min}$, then raised to $270^{\circ} \mathrm{C}$ (with $50^{\circ} / \mathrm{min}$ ) and kept for 2 $\min$.

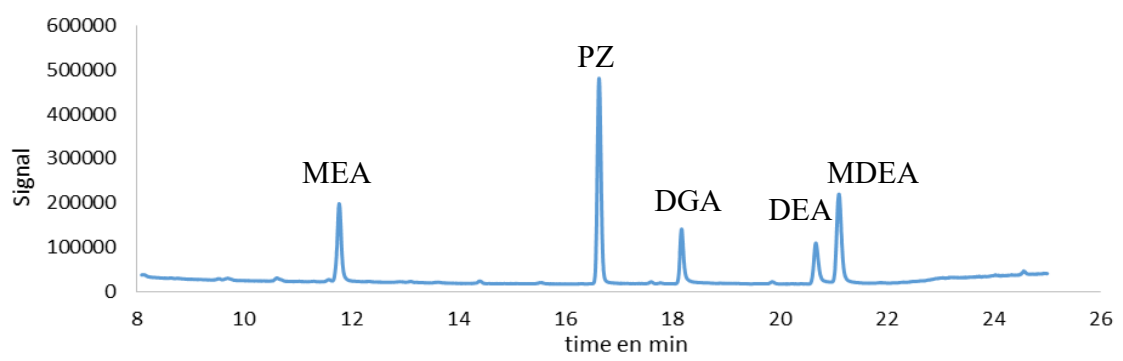

Figure 1: Separation of the five amines after liquid injection of a solution of $100 \mathrm{mg} / \mathrm{L}$ of each amine component in methanol with the column Rtx-Volatile Amine 
With regard to the conformity assessment of biomethane, it was aimed to use sorbent tubes as transfer standard. Therefore the next step of the study is to spike amine solutions on sorbent tubes. A quantification method development is ongoing and will be tested with real biomethane samples.

\subsection{Terpenes analysis}

Two methods involving $\mu$ GC-TCD and TD-GC-MS were developed and compared in order to monitor terpenes in biomethane.

Two columns were compared by TD-GC-MS. The first column was a $5 \mathrm{MS}$ (30m x 0.25 $\mathrm{mm} \times 0.25 \mu \mathrm{m})$. Despite several temperature programme tested, the separation was still non satisfactory for the two last peaks corresponding to d-limonene and p-cymene (Figure 2).

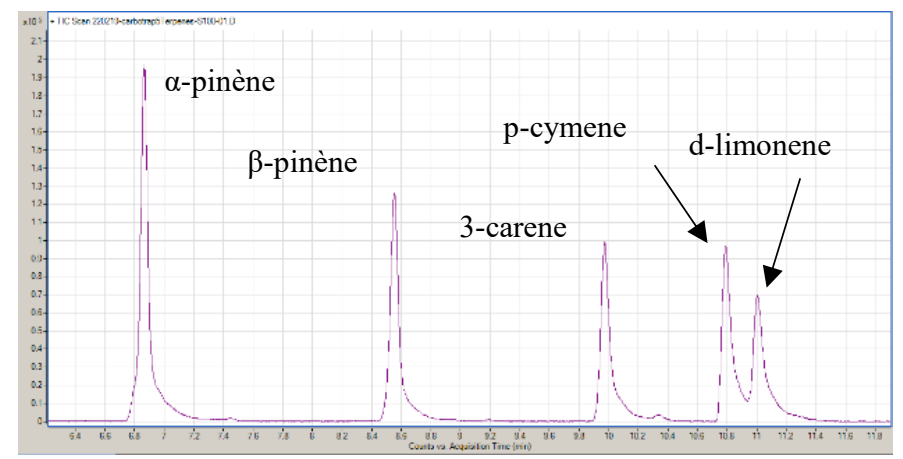

Figure 2: Chromatogram obtained after the analysis of a Carbotrap C300 tube (sampled with $200 \mathrm{~mL}$ of mix 1) with the column 5MS.

The sampled tubes were then analysed by TD-GC-MS with a DB-624 column. Results were more encouraging as the separation of the last two peaks was better than with the previous column (Figure 3). However, the resolution of the peaks was lower than 1.5. In order to precisely quantify the corresponding peaks, we suggest to perform specific ion extractions: 68 for d-limonene and 119 for p-cymene. In terms of sensibility, limits of quantifications were in the range of $2 \mathrm{ppb}$.

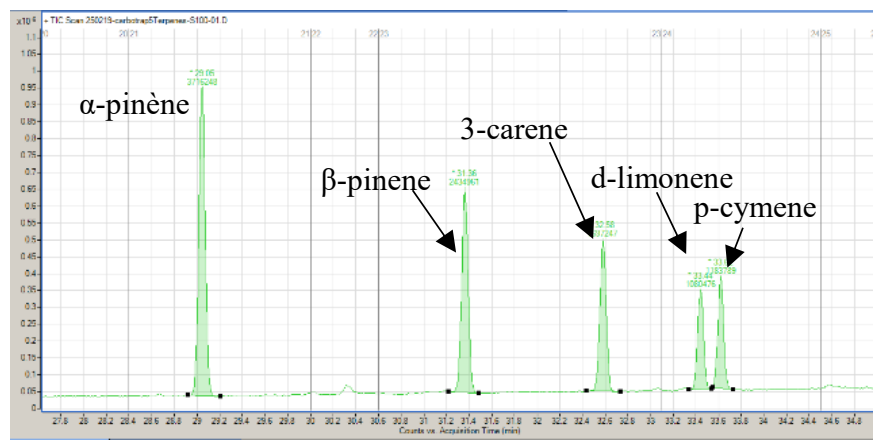

Figure 3: Chromatogram obtained after the analysis of a Carbotrap C300 tube (sampled with $100 \mathrm{~mL}$ of mix A) with the column DB-624 
A $\mu$ GC-TCD method was simultaneously developed in order to compare its performances with TD-GC-MS. The selected column was CP Sil $5 \mathrm{CB}(6 \mathrm{~m})$ heated at $90^{\circ} \mathrm{C}$. An example of obtained chromatogram is given in Figure 4. In terms of sensibility, limits of quantifications were in the range of $2 \mathrm{ppm}$.

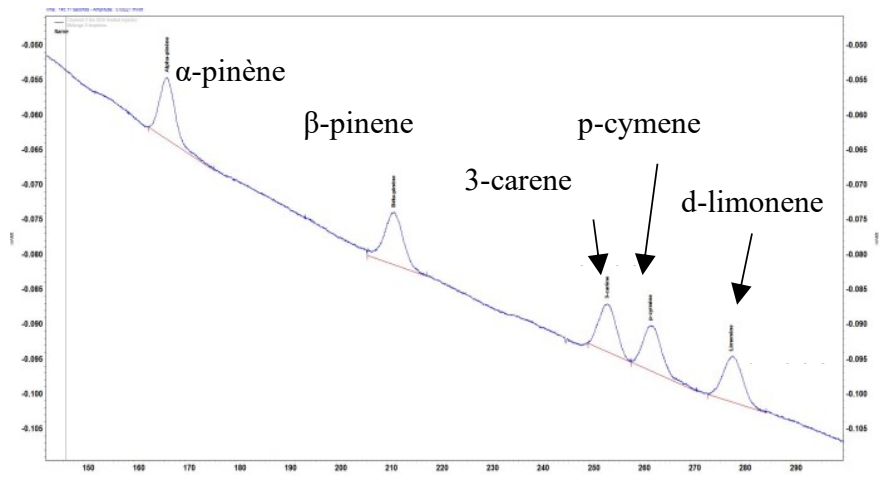

Figure 4: Chromatogram obtained after the analysis of the mix A by $\mu G C-T C D$.

As terpenes start to be problematic at $2 \mathrm{ppm}, \mu \mathrm{GC}$-TCD appears to be an adapted method for their monitoring. Moreover, the method is fully adapted for an onsite and online use, and is less expensive in comparison to TD-GC-MS method. Indeed, the latter is more adapted for trace measurements compounds.

\subsection{Ammonia analysis}

Two methods were compared for ammonia analysis in biomethane: $\mu$ GC-TCD and OFCEAS. Despite their different technologies, both methods are adapted for online and onsite use.

Several concentrations of ammonia in methane were injected by $\mu$ GC-TCD: 50, 40, 30, 20 and $10 \mathrm{mg} / \mathrm{m}^{3}$, with the aim to estimate limit of quantification. Obtained chromatograms are given in Figure 5. As it can be seen on the chromatograms, limit of quantification of ammonia is in the range of $30 \mathrm{mg} / \mathrm{m}^{3}$, higher than the threshold fixed in the EN 16723 specifications $\left(10 \mathrm{mg} / \mathrm{m}^{3}\right)$ [2]. Thus, $\mu \mathrm{GC}-\mathrm{TCD}$ does not seem to be suitable for this application.

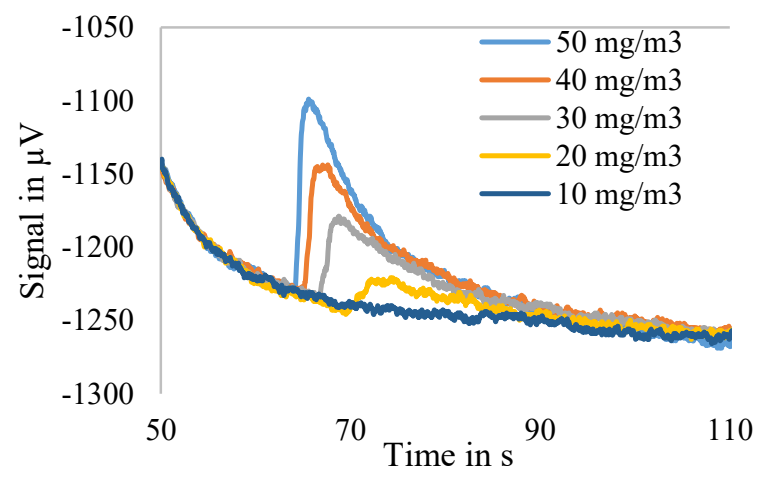

Figure 4: Chromatograms obtained after the analysis of ammonia in methane at 10, 20, 30, 40 and 50 $\mathrm{mg} / \mathrm{m}^{3}$. 
OFCEAS technology through the ProCeas ${ }^{\circledR}$ from ap2e was tested. First results are encouraging as limit of quantification of ammonia is in the range of $1 \mathrm{mg} / \mathrm{m}^{3}$ with this device. Characterisation of the method through accuracy determinations is ongoing.

\section{Conclusions}

Five methods were developed for the monitoring of amines, terpenes and ammonia. Amines separation was performed by TD-GC-MS with a Rtx-Volatile Amine GC column. For terpenes, both TDS-GC-MS and $\mu$ GC-TCD methods showed results in accordance with onsite needs. Regarding ammonia analysis, only OFEAS technology presented performances in accordance with the limit of $10 \mathrm{mg} / \mathrm{m}^{3}$ in biomethane. The limits of quantification of $\mu \mathrm{GC}$ TCD method were too high for its routine use. Next step will be to perform method validation, in order to have information about accuracy and uncertainties of the methods.

\section{References}

[1] Directive (EU) 2018/2001 of the European Parliament and of the Council of 11 December 2018 on the promotion of the use of energy from renewable sources (Text with EEA relevance.) PE/48/2018/REV/1. OJ L 328, 21.12.2018, p. 82-209

[2] NF EN 16723. Natural gas and biomethane for use in transport and biomethane for injection in natural gas network - Part 1: Specifications for biomethane for injection in the natural gas network. 26 May 2017.

[3] Gouedard C., Picq D., Launay F., Carrette P.-L., 2012. Amine degradation in CO2capture. I. A review. Int. J. Greenh. Gas Control 10, 244-270.

[4] 2-E.A. Polman, H. Top, B. Gerritsen, A. Rekers, Development of existing and new measurement technologies for determination of the gas composition, 2015, EDGaR, GT150029.

[5] Arrhenius K., Engelbrektsson J., Yaghooby H., Development of Analytical Methods to Gain Insight into the Role of Terpenes in Biogas Plants. J Anal Bioanal Tech 2016, 7:4.

\section{Acknowledgements}

This work was realized within the the EMPIR project 16ENG05 Metrology for Biomethane. The authors would like to acknowledge the funding from the EMPIR programme co-funded by the Participating States and from the European Union's Horizon 2020 research and innovation programme. 